\title{
Tradutores e tradução na lírica portuguesa dos séculos XX e XXI José Bento, Vasco Graça Moura e Armando Silva Carvalho
}

\author{
Maria António Hörster \\ Universidade de Coimbra
}

\begin{abstract}
Resumo: 0 artigo insere-se numa investigação em curso sobre figuras de tradutores/as e imagens da tradução na literatura portuguesa, seja no domínio da ficção narrativa, da lírica ou da diarística. 0 texto constitui no essencial uma apresentação e uma tentativa de análise de poemas de José Bento, de Vasco Graça Moura e de Armando Silva Carvalho, nos quais estes poetas dão testemunho da sua actividade enquanto tradutores, articulando-se as autoimagens aí contidas com as grandes questões da tradução.
\end{abstract}

Palavras-chave: Tradução, José Bento, Vasco Graça Moura, Armando Silva Carvalho

\begin{abstract}
In previous studies I have sought to evince the specific relevance of Walter Scott's Ivanhoe (translated in 1837, 1838 and 1851) for the Portuguese historical novel of the Romantic Period, by highlighting the esteem in which that particular novel was held in the mid-1800s and the circulation in writings by Portuguese authors of thematic and narrative motifs that may have been derived therefrom; and I have additionally examined the ways in which Ivanhoe was adapted for the stage by Alfredo Possolo Hogan in Keywords: translation, José Bento, Vasco Graça Moura, Armando Silva Carvalho
\end{abstract}


Nos últimos anos tenho procurado auscultar a presença de figuras de tradutores/as e imagens da tradução na literatura portuguesa, tendo já apresentado dois pequenos textos sobre o tema. ${ }^{1}$ Indagar se uma actividade tão importante como é a da tradução tem obtido alguma visibilidade nos nossos textos literários, procurar averiguar se os nossos escritores se apercebem da sua importância e do quanto dependem dela para a sua projecção internacional, se dispõem, eles mesmos, da experiência de tradutores, que relações estabelecem entre a sua criação própria e a sua prática tradutiva, que imagem formam desta modalidade de produção textual e dos seus obreiros, são questões apaixonantes que sem dúvida merecem a nossa atenção. No meu primeiro texto sobre o assunto, centrei a atenção em autores como Miguel Torga (1907-1995), nomeadamente no seu Diário (19411993), em romances de Maria da Graça Azambuja (1916?-1993), de José Régio (19011969), de Teolinda Gersão (n. 1940), de Urbano Tavares Rodrigues (1923-2013), em contos de Cristóvão de Aguiar (n. 1940) e numa novela de Mário Cláudio (n. 1941). Com excepção do que se verifica nos apontamentos diarísticos de Torga, em que se nota uma marcada linha evolutiva no que respeita à sua opinião sobre a tradução, sobre os textos traduzidos e sobre os tradutores - olhados com cepticismo nos primeiros volumes do Diário e objecto de exaltação e de louvor para o final da obra ${ }^{2}$-, exceptuando igualmente o que ocorre na novela de Mário Cláudio - que representa uma interpretação do heterónimo pessoano Bernardo Soares, simples ajudante de guarda-livros de quando em quando solicitado a fazer traduções comerciais - e tirando ainda uma breve referência em Teolinda Gersão, o que se nos depara no geral das obras narrativas abordadas é uma imagem pouco abonatória da actividade e dos seus agentes. Dado o pendor realista dessas obras, não é de estranhar que a tradução seja apresentada sobretudo à luz dos parâmetros sociais em que é exercida, prefigurando-se, de maneira geral, como uma actividade desprestigiada, por via de regra ocasional, levada a cabo por amadores sem preparação específica, por quem tenha alguns conhecimentos de línguas, e enquanto recurso, quase sempre desesperado, para suprir carências económicas. Deparam-se-nos, pontualmente, finas observações sobre a psicologia de quem traduz, mas na quase totalidade dos casos essas referências encontram-se desprovidas de qualquer reflexão teórica sobre o que está em jogo quando se transfere uma 
obra de uma língua/cultura para outra. Exercida no geral com indiferença ou a contragosto, em Maria da Graça Azambuja porém a tradução é vista também como fonte de prazer e de enriquecimento intelectual. ${ }^{3}$ Por sua vez, a dimensão crítica e reflexiva manifesta-se, ainda que timidamente, no único exemplo de escrita diarística abordado, precisamente o Diário de Miguel Torga, percebendo-se da parte do escritor a experiência de autor multiplamente traduzido. ${ }^{4}$

Desde a publicação desse primeiro estudo, tem sido possível encontrar outros afloramentos fugazes destas questões, por exemplo na ficção narrativa de autores de preocupações neorrealistas como Maria Judite de Carvalho, Augusto Abelaira, Urbano Tavares Rodrigues, Baptista-Bastos, que confirmam a imagem negativa e socialmente condicionada da prática da tradução.

Panorama muito diferente se nos apresenta nos testemunhos que aqui vêm à colação. Em primeiro lugar, estamos perante poemas, o que, logo à partida, leva a esperar uma maior economia e densidade da expressão e, também, uma carga emocional mais forte. Determinante para o clima que os informa é o facto de os seus autores serem escritores com larga produção poética e, principalmente, com uma ampla experiência de tradução, nomeadamente no domínio da lírica. ${ }^{5}$

Comecemos por centrar a nossa atenção numa composição de José Bento (n. 1932), poeta que colaborou em revistas de poesia de meados do século passado, como Árvore, Sísifo, Eros, Cadernos do Meio-Dia, tendo sido um dos fundadores da Cassiopeia. Entre 1963 e 1969, fez parte da redacção da revista O Tempo e o Modo. Tem exercido a crítica literária em numerosos jornais e revistas, designadamente na Colóquio-Letras e na Brotéria. José Bento alcançou especial distinção como tradutor de literaturas em língua espanhola e divulgador entre nós das letras de Espanha e da América Latina. ${ }^{6}$ Traduziu uma extensa lista de autores e autoras, como sejam San Juan de la Cruz e Fray Luis de León, Jorge Manrique e Bécquer, tendo publicado antologias de Garcilaso de la Vega, Santa Teresa de Jesús, Quevedo, M. Machado, A. Machado, J. R. Jiménez, Vicente Aleixandre, Lorca, Cernuda, Miguel Hernández, A. Crespo, Gil de Biedma, Francisco Brines, J. A. Ramos Sucre, Vallejo, Neruda; uma Antologia da Poesia Espanhola do «Siglo de Oro» em dois tomos, Renascimento 
e Barroco; uma Antologia da Poesia Espanhola Contemporânea (desde Unamuno aos novíssimos); uma Antologia da Poesia Espanhola das Origens ao Século XIX. Traduziu igualmente ficção em prosa: La Celestina, de Fernando de Rojas, obras de Unamuno, Juan Ramón Jiménez, Ortega y Gasset, Jorge Luis Borges, María Zambrano, J. M. Arguedas, Octavio Paz, Ignacio Martínez de Pisón e, no âmbito do teatro, Calderón de la Barca, Valle-Inclán, Federico García Lorca. Em 2005 deu a lume uma versão portuguesa do D. Quixote, de Cervantes. ${ }^{7}$ Mas o seu envolvimento com a tradução não se manifesta apenas enquanto tradutor nem a um nível estritamente pessoal. Desde há muito que José Bento se mostra atento ao fenómeno da tradução e ao trabalho de outros tradutores, como por exemplo já num texto de 1963, em que reconhecia o valor literário das traduções de Paulo Quintela, que via como "o tradutor a quem a poesia portuguesa deste século mais deve" (Bento 1963: 87). ${ }^{8} \mathrm{Na}$ colectânea em que se inclui o poema que passaremos a analisar, encontra-se igualmente uma composição que dedica a Ruy Belo pelas suas versões de Jorge Luis Borges, na qual exalta o seu trabalho enquanto tradutor. ${ }^{9}$

O poema que nos ocupa, por sua vez, é também dedicado a um casal de tradutores do país vizinho: ela, Pilar Gómez Bedate, académica e tradutora, catedrática de Literatura Espanhola e de Literatura Comparada; ele, Ángel Crespo, seu marido, poeta, ensaísta, crítico de arte e tradutor, por exemplo de autores portugueses como Fernando Pessoa, António Osório, Dinis Machado, entre outros. ${ }^{10} 0$ poema foi inicialmente publicado em Espanha, em 1986, integrado em Textos para Ángel Crespo, com tradução precisamente de Pilar Gómez Bedate, ${ }^{11}$ e, mais tarde, integrado na colectânea de poemas de José Bento Silabário, de 1992:

EU TRADUTOR, TRAIDOR

A Pilar Gómez Bedate e Ángel Crespo

Não me dói o que de mim perdi.

Busco, não o encontro, mas recolho

sua exalação, não mais

que a memória alumiando

quanto já não regressa:

fogo hibernal que se mantém do frio. 
Relanceio o que toquei não sendo meu:

palavras,

cicatrizes indefesas

numa boca, num lugar, numa data.

Amei-as sem lucidez.

Profanação?

A quem prestarei contas?

Muitos

reivindicam o que é seu, e transmutei

sem consciência, com avidez tão cega

que não soube transmitir sua inteireza,

ufano ao supor reter seu fundo aroma.

Dissipei tanto fulgor alheio

ao querer dá-lo qual se me pertencesse,

sem o remorso e a vergonha

de o oferecer como se não o tivesse magoado. (Bento 1992: 98)

O título da composição parte daquele que será o mais conhecido e incontornável adágio quando se fala de tradução, traduttore, traditore, ${ }^{12}$ combinando-o com a fórmula inicial da confissão: "Eu, pecador, me confesso". Assim enquadrado, o texto configura-se como acto de contrição pessoal de um tradutor. 0 clima de religiosidade anunciado no título perpassa por todo o texto e sustenta-se, por exemplo, na isotopia formada por vocábulos e expressões como "profanação", "prestar contas", "remorso", e ainda "sem consciência", "avidez", "ufano", "dissipei" e "vergonha", que enunciam as culpas e a consciência das faltas que cometeu enquanto tradutor. Com esta disposição, o poema recria o tom religioso e meditativo de muita da poesia deste autor. Num texto a que deu o título de "Uma poética do apagamento", José Tolentino Mendonça observa em síntese, e com agudeza, que "A poesia de José Bento tem a respiração e a intensidade de uma disciplina espiritual." (Mendonça 2003: 6).

A composição é informada por um gesto memorialista no inverno da vida, na atitude de quem faz um balanço do que ficou para trás e assume as responsabilidades, começando o 
eu lírico por contrapor a sua obra própria e as traduções de textos de outros escritores. Se não lhe doem as perdas no foro da produção pessoal, doem-lhe todas as que, por incapacidade ou culpa suas, infligiu aos textos alheios que transmudou, levando-os à perda do seu fulgor original. Acusa-se, sobretudo, de oferecer esse fulgor "como se não o tivesse magoado", ou seja, a tradução é vista como ofuscação de brilho, perda portanto, como atentado, e até como agressão, tanto mais culposa quanto as vítimas, as palavras, não têm possibilidade de se defender. Inépcia, amor cego, vaidade, desejo de apropriação de textos alheios são pecados de que aqui se confessa. 0 poema respira certa ambiência barroca, sobretudo pela insistência na ideia da vanitas, e o verso livre e a solenidade da dicção sublinham, já a nível formal, a proximidade com o versículo bíblico.

Dum ponto de vista da teoria da tradução, diríamos que José Bento assume plenamente a imagem tradicional e romântica de originalidade e do carácter sagrado do texto dito original, de que decorre a incontestada superioridade deste em relação ao texto traduzido, um texto segundo, derivado e sempre imperfeito, e a do autor do original em relação ao tradutor. ${ }^{13}$ É uma visão que ultimamente tem sido amplamente revista, reconhecendo a teoria actual a dimensão autoral do tradutor, visão partilhada por alguns tradutores, como aquele que seguidamente aqui abordarei. ${ }^{14}$ Pessoalmente, entendo que o texto traduzido se articula numa voz dual, em que se fundem a do autor dito original e a do tradutor.

Bem diferente é o tom que encontramos no seguinte soneto de Vasco Graça Moura (n. 1942), também ele dedicado a outro tradutor, Joaquim Francisco Coelho, lusitanista brasileiro de Harvard, em que o autor português ludicamente discreteia sobre as traduções que um e outro fizeram do famoso poema "Der Panther", de Rainer Maria Rilke. O soneto começou por ser publicado no blogue ABRUPTO, de José Pacheco Pereira, em 2003, conforme nota que Graça Moura apõe ao seu volume Laocoonte, rimas várias, andamentos graves, de 2005 (Moura 2005: 187). Nesta colectânea lírica, encabeça um conjunto de quinze interessantíssimos e divertidíssimos sonetos, que infelizmente não posso aqui trazer, em torno por exemplo do poema rilkiano, das duas traduções em causa ou de Lou Andreas Salomé, imaginada também ela como pantera. 
aretnap a pantera,

um divertimento em ressonâncias

(para Joaquim Francisco Coelho, por termos ambos traduzido

"Der Panther”, de RAINER MARIA RILKE)

1.

fomos os dois à caça da pantera

que estava já da jaula sob o tecto;

na mesma língua e em cada idiolecto,

apanhá-la inteirinha, quem nos dera!

mas clonado, que fosse não se espera

dorso verbal em músculo inquieto,

e ao lê-lo, eu me felino e me arquitecto,

pois me pantero, e mais, se reverbera

noutro registo a língua subtil que,

de cada vez que a dupla se faz frente,

é jogo especular no abismo, acaso

devíamos levar a rainer rilke

esta parelha opaca e transparente

à trela, quando formos ao parnaso. (Moura 2005: 143 e 145)

Estamos muito longe do sentimento de culpa que encontrámos em José Bento. Aqui encontramos brincadeira, alegria, celebração. No tom lúdico que o subtítulo anuncia, o soneto concebe-se como um divertimento, como uma variação imaginosa e despreocupada. Tendo-lhe sido enviada uma tradução para português do famoso poema "Der Panther", de Rainer Maria Rilke, da autoria de Joaquim Francisco Coelho, algum tempo depois de ter publicado a sua própria tradução do poema, ${ }^{15}$ Graça Moura sente-se irmanado a esse outro mesteiral das letras. Recuperando o clima arcadiano do companheirismo de poetas, dirige- 
se a este outro tradutor, a quem sugere uma subida conjunta ao Parnaso, para apresentar a Rilke o duplo troféu. Não só estes motivos arcadianos, também a linguagem, com os numerosos hipérbatos, recriam o ambiente classicizante que Graça Moura tantas vezes convoca nos seus textos.

A imagem da tradução aqui prevalecente é, já por sugestão do tema, a da caça. Desde a Antiguidade muitas têm sido as metáforas propostas para captar a essência da tradução, desde a do pagamento monetário em igual valor, sopesado por junto e não restituído pelo mesmo número de moedas, que encontramos em Cícero, à da conquista, em S. Jerónimo, ou à do direito e avesso de uma tapeçaria, em Cervantes, ou ainda àquela muito habitual de um mesmo conteúdo vertido em vasilhas diferentes, às quais se vêm somar inúmeras outras. Não é a imagem jeronimita da conquista que Graça Moura nos transmite, mas a da caça, em que certamente cabe o elemento da força e da submissão, mas na qual sobreleva, no jeito que Graça Moura lhe dá, a ideia do divertimento e do prazer.

O terceiro poema que aqui trago é da autoria de Armando Silva Carvalho (n. 1938) e foi publicado na sua colectânea lírica Sol a sol, de 2005. Poeta e ficcionista, Armando Silva Carvalho dispõe ele mesmo de ampla experiência como tradutor. Desde a década de sessenta até à actualidade, o seu nome figura como tradutor de dezenas de originais de língua francesa, inglesa, italiana, espanhola, sueca, neerlandesa, grega, japonesa, sendo muito grande a variedade dos géneros e temáticas em que se move. Entre os muitos autores que traduziu, refiram-se, por exemplo, Vicente Aleixandre, Samuel Beckett, Marguerite Duras, Jean Genet, Roger Garaudy, Aimé Césaire, Yasunari Kawabata, Renate Dorrestein, Níkos Kazantzáki, Cristina Campo, Carmen Martín Gaite, Rosa Montero, Maria Bellonci, David Trueba, Ingmar Bergman, Alberto Méndez.

Leia-se o texto:

O tradutor

Lentamente traduzo a ruptura do mundo

Com o novo século.

Escrevo com os olhos ardidos 
Pelas novas visões do passado.

Levanto um braço e procuro

Mais uma palavra suada.

Faço o trabalho no brilho embaciado

Da noite.

Retiro lentamente da cabeça

Incrustações de vícios

Pequenas recordações de males menores

Ácidas partículas.

Sorvo o tédio.

Agora que o silêncio é uma crosta de sangue

Nos meus ombros

Recomeço a coçar-me.

Valerá a pena? Não faço disto a festa.

Sou simples.

Sou o intermédio.

Se o meu olhar souber seguir as novas pistas

Pisarei paciente a luz dinâmica

Ouvirei o murmúrio dos ordenadores

Sentirei os sinais dos guias intérpretes

Despirei essas criaturas secas

Contíguas ao terror

E conformadas.

Sentadas nas mais recentes palavras

As multidões querem negociar

A tradução do amor nas almas desarmadas.

Mas eu não esqueço.

Faço como quem transporta diamantes

No estômago

Prata na cabeça dos dedos. 
Desmontar pessoas é um ofício divino,

Vil, apaixonado.

E as pessoas amam o dextro financeiro,

A silhueta de ouro, o desnaturado.

Todas as noites apaziguam o espírito.

E eu contemplo com o pavor

Lúcido dos cegos

A risonha coroa do triunfo.

Ao longe as crianças despertam

Com o olhar turvo de cimento e espiam

Na madrugada os intraduzíveis apelos ao conhecimento.

Surgem os primeiros revérberos do sol

E eu passo a mão abstracta, ingénua, envelhecida

Pelos seus cabelos eriçados

De sono.

Os seres vivos desaparecem da superfície do texto.

E eu sonhei uma prótese da escrita

Uma conversão em minérios de sexo

Em filmes ortopédicos

Em caligrafias expostas nas paredes

Do mundo.

Mas o sonho não é proposta digna deste século

É um esboço manual da delinquência.

Um dedo singular na cúpula divina

Da nossa impossível renascença.

E por isso traduzo. (Carvalho 2005: 23-25)

É um poema não fácil. No modo irónico tão próprio do autor, o poema dá-se a ler como uma heteroimagem de qualquer tradutor (considere-se o título), mas sobretudo como 
autoimagem de um eu lírico em que o tradutor Silva Carvalho se encontra implicado. ${ }^{16}$ Creio que podem distinguir-se duas grandes sequências. A primeira, que abre com a proclamação altissonante "Lentamente traduzo a ruptura do mundo / Com o novo século.", desliza, num movimento descendente de bathos, até às afirmações "Não faço disto a festa. / Sou simples. / Sou o intermédio." Aqui parecem reunidas as tradicionais imagens da escrita tradutiva como uma escrita apagada, sem júbilo, e a do tradutor como um ser a quem cabe ser humilde, dada a sua função de mero intermediário. Note-se a substantivação do adjectivo: "Sou o intermédio." A segunda, que vai até ao final do poema, descreve um movimento contrário: partindo dessa atitude inicial de auto-apagamento, eleva-se até à imagem do tradutor como construtor da nossa (impossível) renascença. Crítica social, crítica da linguagem, consciência da responsabilidade do tradutor, são alguns dos temas aqui apresentados.

Encontramos neste poema reunidos alguns dos tópicos mais frequentemente associados à tradução e ao tradutor: a solidão, a paciência, a perseverança, a humildade, o sofrimento, mesmo físico, a paixão com que se devota ao seu trabalho, o fraco reconhecimento social, mas, por outro lado, também a consciência do valor cívico da sua intervenção, do poder subversivo da palavra, da dimensão utópica da sua actividade. Ironia, auto-ironia, mordacidade e sarcasmo convivem com o pathos, o sonho, a paixão e a utopia, e esta convivência parece fazer jus aos paradoxos sociais e psicológicos da prática da tradução. Tomando como ponto de partida a sua própria actividade, Armando Silva Carvalho tece uma crítica profunda à sociedade actual, dominada por uma cultura do divertimento, sem profundidade e sem consciência histórica e linguística. ${ }^{17}$ Traduzir é guardar a memória, é resistir, por exemplo às leis do mercado, à futilidade, é passar o testemunho às gerações vindouras, é intervir socialmente.

Muito diferentes entre si, os três textos apresentados - um mais íntimo e de tonalidade mais religiosa, outro mais puramente lúdico e convivente, um terceiro, ainda, mais especulativo, ultrapassando os limites do processo de tradução para se deter numa crítica à sociedade e à linguagem - mostram como estes poetas tradutores têm consciência das dificuldades do ofício de traduzir, da dimensão utópica da tradução portanto, mas 
também do prazer que daí lhes advém, do amor à palavra, da responsabilidade que lhes cabe na viagem dos textos - e estamos dentro de um dos temas do nosso colóquio -, no sentido da construção de uma Weltliteratur.

\section{Bibliografia}

Azambuja, Maria da Graça (s. d. /1954?/), Bárbara Casanova, Lisboa, Parceria António Maria Pereira.

Bento, José (1963), “A Tradução das «Elegias de Duino» de Rainer Maria Rilke”, in O Tempo e o Modo, N. 5, Maio de 1963, pp. 87-93.

-- (1992), Silabário, Lisboa, Relógio d’Água.

-- (2003), Alguns Motetos. Selecção e prólogo de José Tolentino Mendonça, Lisboa, Assírio \& Alvim.

Carvalho, Armando Silva (2005), Sol a sol, Lisboa, Assírio e Alvim.

Hörster, Maria António (2011), "Tradutores e tradução na literatura portuguesa dos séculos XX e XXI", in Miscelânea de Estudos em Homenagem a Maria Manuela Gouveia Delille, Volume I/ Band I. Coordenado por Maria Teresa Mingocho, Maria de Fátima Gil, Maria Esmeralda Castendo, Coimbra, Faculdade de Letras da Universidade de Coimbra, Centro de Investigação em Estudos Germanísticos, Edição de MinervaCoimbra, pp. 643-658.

-- (no prelo; a publicar na Miscelânea de Homenagem a Maria Irene Ramalho Sousa Santos), “Da estirpe de Sísifo e Mnemosine. Notas sobre o poema 'O tradutor', de Armando Silva 
Carvalho".

Llosa, Mario Vargas (2012), A Civilização do Espetáculo, Lisboa, Quetzal Editores.

Mark, Davie (2012)

http://blog.oup.com/2012/09/traduttore-traditore-translator-traitor-translation/

Marnoto, Rita (2013), “Pelas florestas da noite. Vasco Graça Moura tradutor e poeta”, in Rassegna Iberistica, N. 98, Abril de 2013, Bulzoni Editores, pp. 91-102.

Mendonça, José Tolentino (2003), “Uma poética do apagamento", in: Bento, José Alguns Motetos. Selecção e prólogo de J. T. M., Lisboa, Assírio \& Alvim.

Moura, Vasco Graça (2003), As rimas de Petrarca, Lisboa, Bertrand.

-- (2005), Laocoonte, rimas várias, andamentos graves, Lisboa, Quetzal Editores.

-- (2006), poesia 2001/2005, Lisboa, Quetzal Editores.

Ribeiro, Nuno (2006), "Primeiro prémio Luso-Espanhol de Arte e Cultura para José Bento", Público, 12 de Dezembro, p. 30.

Torga, Miguel (1999), Diário, 2 vols., 2.․ edição, Lisboa, Publicações Dom Quixote. 


\section{NOTAS}

${ }^{1}$ Um dos textos, "Tradutores e tradução na literatura portuguesa dos séculos XX e XXI" (Hörster 2011), encontra-se publicado na miscelânea de homenagem a Maria Manuela Delille; o outro, "Da estirpe de Sísifo e Mnemosine. Notas sobre o poema 'O tradutor', de Armando Silva Carvalho”, en contra-se ainda no prelo e virá a integrar a miscelânea de homenagem a Maria Irene Ramalho (vd. Bibliografia).

${ }^{2}$ No discurso que proferiu aquando de uma homenagem que lhe foi prestada pelo Goethe-Institut de Coimbra, confessava: “(...) E o pobre poeta de qualquer S. Martinho de Anta, que sonha com o seu canto a ecoar para além das fronteiras que o limitam, é nessas almas sintonizadas e mediúnicas que confia. São elas as difusoras mágicas das suas palavras, que procuram entender em todos os recônditos sentidos e preservar vivas e equivalentes na transplantação verbal. Nunca será por demais exaltado o serviço que prestam à humanidade esses obreiros de uma outra comunicação dos santos, terrena, encarnada, naturalmente oposta à sobrenatural do Credo. Se nos faltassem, ficariam sem respostas inimagináveis interrogações, apelos e desafios. As esfinges que interpelam sibilinamente os viandantes à entrada de todas as Tebas da existência, são monstros de carne e osso e papel e tinta. E os seus enigmas, avisos ambíguos e catárcticos que, depois de fielmente decifrados e trasladados, abrem caminho à ânsia libertadora de Gregos e Troianos." Cf. entrada de 23 de Novembro de 1990 (Torga 1999: 1693-1694; citação 1693).

${ }^{3}$ No romance Bárbara Casanova (s. d./ 1954?) de Maria da Graça Azambuja, após uma noite de trabalho a traduzir um romance de um escritor norueguês, a protagonista é invadida pelos seguintes sentimentos: "Por fim, desaparecida a tensão em que estava, as dificuldades diminuíram. Não pensava em comida. Um pouco de café e de leite, de fruta, de pão racionado... Ao seu espírito abriam-se mais largas perspectivas. Fundia-se no mundo do Escritor e encontrava-se com os seus pensamentos mais subtis, por uma estrada de seda onde se lhe deparava Beleza e imprevisto. De nada precisava e sentia-se triunfante por não agradar nem desagradar a alguém. Foi uma quinzena esgotante de uma existência quase feliz." (Azambuja

s. d /1954?/: 256-257).

${ }_{4}$ As estreitas relações de amizade que durante muito tempo manteve com um dos mais proficientes tradutores literários do século que passou, Paulo Quintela, ter-lhe-ão certamente acicatado o interesse pelo fenómeno.

${ }^{5}$ A coincidência, na mesma pessoa, do poeta e do tradutor de poesia é um fenómeno que entre nós se vem manifestando com frequência crescente desde meados do século passado. Poderíamos citar os nomes de Sophia de Mello Breyner e Andresen, Eugénio de Andrade, David Mourão Ferreira, Monteiro-Grillo / Tomás Kim, Jorge de Sena, Fernando Guimarães, Egito Gonçalves, José Bento, Mário Cesariny de Vasconcelos, Herberto Helder, Ruy Belo, Pedro Tamen, Luiza Neto Jorge, Vasco Graça Moura, Armando Silva Carvalho, Nuno Júdice, Ana Luísa Amaral, entre muitos outros. 
6 Pela sua actividade enquanto tradutor tem sido agraciado com numerosas distinções nacionais e estrangeiras, como sejam: Prémio de Tradução, PEN Clube Português / Associação Portuguesa de Tradutores de 1985, pela Antologia de Poesia Espanhola Contemporânea; Prémio de Tradução, PEN Clube Português / Associação Portuguesa de Tradutores (ex-aequo) de 2005, pela obra O Engenhoso Fidalgo D. Quixote de la Mancha. Grande divulgador da cultura hispânica, foi-lhe atribuída, em Espanha, a Medalla de oro al Mérito de Bellas Artes, em 1991; em 1992 foi condecorado com a Ordem do Infante D. Henrique e recebeu o Prémio Luso-Espanhol de Arte e Cultura em 2006, pela sua contribuição para o reforço dos laços ibéricos. Foi também o vencedor do "Prémio de Tradução Paulo Quintela 2002", atribuído pela Faculdade de Letras da Universidade de Coimbra.

${ }^{7}$ Sendo poeta, a sua primeira obra poética, Sequência de Bilbau, foi publicada 20 anos após o início do seu trabalho como tradutor (Ribeiro 2006).

${ }^{8}$ Da relação entre poetas e tradutores e das qualidades necessárias a estes últimos para que exerçam devidamente o seu mister, dão conta as palavras de abertura deste texto: "Raríssimos poetas estrangeiros têm encontrado em Portugal os leitores com o amor e a cultura, a humildade e o gosto pela aventura que os transformem em seus tradutores." (Bento 1963: 87).

${ }^{9}$ Esta composição, publicada pela primeira vez na revista Aresta, n. ${ }^{0 s} 7 / 8$, Ponta Delgada, 1984 (cf. Bento 1992: 302), confirma o valor que José Bento atribui à tradução, nomeadamente à tradução poética: “A RUY BELO, / pelas suas Traduções de Jorge Luis Borges // Não te procuro em versos teus somente / ou a compor teu rosto, que mal vi: / sulco diferente me conduz a ti, / que és só luz desde que és o teu poente. // Busco-te nessa pedra ou boca ardente / a defender o que gravaste ali, / ditado por alguém que conheci / pela cifra que abriste e nunca mente. // Trouxeste-me esse arauto sem traí-lo: / os mitos, o ser um outro, o esquecimento / que tudo sorve, pântano tranquilo. // Na máscara a que deste a tua voz / leio o fogo que, sendo teu, sustento: / ele e tu nesse acorde somos nós." (Bento 1992: 59). Interessante, aqui, a imagem da comunhão de poetas e de tradutores através do texto poético traduzido.

10 Existe, mesmo, um Prémio de Traducción Ángel Crespo, promovido pelo Centro Español de Derechos Reprográficos (CEDRO), pela Asociación Colegial de Escritores de Catalunya (ACEC) e pelo Gremi d'Editors de Catalunya, com o objectivo de homenagear o grande tradutor e humanista espanhol.

${ }^{11}$ Nas "Notas" que José Bento apõe ao volume, contém-se a seguinte informação: “Textos para Ángel Crespo (Diputación de Ciudad Real, 1986): Eu tradutor, traidor (com tradução de Pilar Gómez Bedate)." (Bento 1992: 302).

${ }^{12}$ Desconhece-se a origem deste tão citado adágio, normalmente interpretado no sentido de um juízo negativo sobre quem traduz: incapazes de vencer as barreiras linguísticas e culturais, os tradutores sempre 
"atraiçoariam" os originais. Contrariando esta interpretação corrente, Davie Mark, que começa por estranhar que a sabedoria popular encarnada nos provérbios se tenha preocupado com as dificuldades de uma actividade tão intelectual como é a tradução, admite como mais plausível que o juízo negativo tenha sido originalmente emitido sobre aqueles que, ao invés de falarem claro para o povo ignorante, se serviam de línguas que não lhe eram familiares como instrumento de poder. Entre esses estariam os padres, os juristas e os médicos. Em I promessi sposi Manzoni criou duas personagens paradigmáticas a este respeito. (Mark 2012). 13 O poema acima referido "A RUY BELO, / pelas suas Traduções de Jorge Luis Borges" retoma alguns dos motivos de "Eu Tradutor, Traidor", como sejam o da primazia do texto original sobre o texto traduzido, o da traição e o do fogo. Também o poema "Tua voz transferes para outros", da mesma colectânea, se debruça sobre a tradução, retomando a imagem culposa que encontrámos no poema analisado (Bento 1992: 286). A tradução aparece como logro e ilusão, não conseguindo nunca o tradutor abdicar da sua própria voz.

${ }^{14}$ Os próprios tradutores vêm cada vez mais tomando consciência do seu estatuto de co-autores. Significativa a este respeito é, por exemplo, a capa do volume de traduções de Sonette an Orpheus, de Rainer Maria Rilke, por Vasco Graça Moura. No lugar habitualmente reservado à indicação do nome do autor, Vasco Graça Moura coloca o seu próprio nome, alterando o título da obra para Os Sonetos a Orfeu de Rainer Maria Rilke. A mesma atitude é retomada no caso da sua tradução de Il Canzoniere, de Petrarca, que deu à estampa sob o título de $A s$ rimas de Petrarca. Em termos discursivos, manifesta expressamente esta mesma posição na introdução à colectânea por último referida: “(...) nada disto quer dizer que a tradução não abra ensejo à expressão da personalidade do tradutor. Pelo contrário. 0 tradutor também é 'autor'. A objectiva não é apenas a língua através da qual se espreita: tanto ela como uma câmara fotográfica utilizada fazem parte de um complexo psicossomático (o da personalidade e da capacidade intelectual, emotiva e técnica, e das próprias concepções do tradutor quanto à maneira de executar a sua tarefa)." (Moura 2003: 32).

15 No artigo "Pelas florestas da noite. Vasco Graça Moura tradutor e poeta", Rita Marnoto (2013) parte do poema "a opção" (Moura 2005: 140-141), para se debruçar sobre a oficina do tradutor Vasco Graça Moura. No decurso do seu texto, vem a deter-se no poema aqui analisado, referindo as circunstâncias que lhe deram origem e a densa teia de relações que se estabelecem pela via da comunicação em rede, nomeadamente com o blogue de Pacheco Pereira.

${ }^{16}$ Para uma análise mais detalhada do poema, vd. Hörster (no prelo).

17 O desaparecimento, nos nossos dias, a que está votada a cultura, no sentido que tradicionalmente se atribui a esse vocábulo, e a sua substituição por actividades de entretenimento fúteis e mesmo desprestigiantes são o tema do ensaio de Mario Vargas Llosa A Civilização do Espetáculo (vd. Bibliografia). 